\title{
Radionuclide Syringe Counts
}

National Cancer Institute

\section{Source}

National Cancer Institute. Radionuclide Syringe Counts. NCI Thesaurus. Code C69292.

The total amount of radioactive material present in a syring e prior to administration, measured as counts per minute. 